\title{
ANATOMICAL VARIATIONS OF THE PARANASAL SINUSES AND THE NASAL CAVITY
}

\author{
Shrestha $K^{1}$, Acharya $R^{2}$, Joshi $R^{1}$, Maharjan $S^{1}$, Adhikari $D^{1}$
}

${ }^{1}$ Department of Otolaryngology, Head and Neck Surgery and ${ }^{2}$ Department of Radiology, Nepal Medical College Teaching Hospital, Kathmandu, Nepal

\begin{abstract}
Computed tomography (CT) of the para-nasal sinuses (PNS) has nowadays become the investigation of choice for the diagnosis of sinonasal diseases. Numerous sinonasal anatomic variants exist and are frequently seen on CT scans. A sound knowledge of these variations is important not only for diagnosis but also for planning surgery in order to avoid complications. The aim of this study is to investigate the frequency of these variations in patients with sinonasal symptoms and also to determine their relation to sinonasal disease if any. A total of 76 patients were included in the study from August 2017 to July 2018 of which $43(56.6 \%)$ were males and while $33(43.4 \%)$ were females with male to female ratio of 1.3:1. The ages of patients ranged from 14 to 72 years with a mean age of $33.2 \pm 14.2$ years. Out of 76 patients, $68(89.5 \%)$ had at least one type of anatomical variation while 8 (10.5\%) had no variation. Only one variation was seen in $39(51.3 \%)$ patients while $29(38.2 \%)$ had two or more variations. The most common variant was deviated nasal septum (DNS), occurring in 49 (64.5\%) patients followed by concha bullosa (CB) and agger nasi cell (AN) seen in 15 (19.7\%) and 14 (18.4\%) patients respectively. Genderwise, anatomical variations were seen more in males but the difference was not statistically significant. Some variations were seen more on the right side while others on the left. Some variations were present bilaterally. The difference was not statistically significant. The presence of DNS was statistically significant in the study population (p value 0.012 in nonparametric chi square test). The age group 14 to 30 years showed maximum variations though not significant statistically. Therefore, during management of patients with sinonasal symptoms, these variations need to be addressed, if required, surgically. Proper knowledge of both common and uncommon sinonasal variations in our community could help in better surgical planning and overall management of sinonasal disorders.
\end{abstract}

\section{KEYWORDS}

Anatomical variations, computed tomography (CT) scan, paranasal sinuses

\section{CORRESPONDING AUTHOR}

Dr. Kundan Kumar Shrestha,

Department of Otolaryngology \& Head and Neck

Surgery, Nepal Medical College Teaching Hospital,

Attarkhel, Gokarneshwor-8, Kathmandu,

P.O. Box 13344, Nepal,

Email: kundanshrestha9@hotmail.com 


\section{INTRODUCTION}

Computed tomography (CT) of the para-nasal sinuses (PNS) has nowadays become the investigation of choice for the diagnosis of nasal and sinus diseases. ${ }^{1}$ A detailed radiological description of the anatomy of nose and PNS is also required for meticulous assessment of patient before planning endoscopic sinus surgery (ESS). ${ }^{2}$

Numerous sinonasal anatomic variants exist and are frequently seen on sinus CT scans. The most common ones are Agger nasi cells (AN), infraorbital ethmoidal Haller cells (HC), sphenoethmoidal Onodi cells (OC), deviated nasal septum (DNS) and concha bullosa (CB). ${ }^{3-12}$

A sound knowledge of these variations is important not only for diagnosis but also for planning surgery in order to avoid damage to surrounding vital structures like the orbit and the brain. The literature reveals limited data on anatomical variations of nose and PNS in our population. The aim of this study is to investigate the frequency of these variations in patients with sinonasal symptoms who undergo CT scan in our hospital and also to determine their relation to sinonasal disease if any and their clinical relevance in general.

\section{MATERIALS AND METHODS}

This study was carried out at Nepal Medical College and Teaching Hospital (NMCTH), Attarkhel, Kathmandu, Nepal from August 2017 to July 2018. Ethical approval was taken from the Institutional Review Committee (IRC) of NMCTH. Prior informed written consent was taken from all the subjects participating in the study. All patients aged 14 years or above undergoing NCCT (Nose/PNS/Orbit) at NMCTH for various sinonasal problems and willing to give a consent were included in this study. Patients aged less than 14 years, those with history of previous sinonasal surgeries or nasal trauma and those with invasive/extensive sinonasal diseases or sinonasal malignancies were excluded.

CT scans were collected, studied and discussed among the researchers. A unanimous consensus was reached regarding the presence of common anatomical variants like AN, HC, OC, DNS, CB, paradoxically curved middle turbinate (PCMT), septal pneumatisation (SP) and uncinate process pneumatisation (UPP). The data obtained was entered in an excel sheet and analysed using SPSS 16 software.

\section{RESULTS}

A total of 76 patients were included in the study of which 43 (56.6\%) were males and 33 (43.4\%) were females with male to female ratio of 1.3:1. The age of patients ranged from 14 to 72 years with a mean age of $33.2 \pm 14.2$ years.

Out of 76 patients, 68 (89.5\%) had at least one type of anatomical variation while $8(10.5 \%)$ had no variation. Only one variation was seen in 39 $(51.3 \%)$ patients while $29(38.2 \%)$ had two or more variations. The most common variant was DNS, occurring in $49(64.5 \%)$ patients followed by $\mathrm{CB}$ and AN seen in $15(19.7 \%)$ and $14(18.4 \%)$ patients respectively. We found SP in $5(6.5 \%)$ patients, OC in 3 (3.9\%), HC and PCMT in $2(2.6 \%)$ each and UPP in none of the patients.

\begin{tabular}{|lccc|}
\hline \multicolumn{4}{|c|}{ Table-1: Genderwise distribution of anatomical } \\
variations (n=76)
\end{tabular}

\section{Table-2: Laterality of sinonasal anatomical variations $(\mathrm{n}=76)$}

\begin{tabular}{lcccc} 
Type of anatomical variation & Right n (\%) & Left n (\%) & Both $\mathbf{n}(\%)$ & P value \\
DNS & $26(34.2 \%)$ & $20(26.3 \%)$ & $3(3.9 \%)$ & 0.104 \\
Concha bullosa & $3(3.9 \%)$ & $5(6.5 \%)$ & $7(9.2 \%)$ & 0.309 \\
Agger nasi & $6(7.9 \%)$ & $2(2.6 \%)$ & $6(7.9 \%)$ & 0.892 \\
Onodi cell & $2(2.6 \%)$ & $1(1.3 \%)$ & $0(0.0 \%)$ \\
Haller cell & $1(1.3 \%)$ & $1(1.3 \%)$ & $0(0.0 \%)$ \\
Paradoxical MT & $1(1.3 \%)$ & $1(1.3 \%)$ & $0(0.0 \%)$ \\
Uncinate process pneumatisation & $0(0.0 \%)$ & $0(0.0 \%)$ & $0(0.0 \%)$ \\
Septal pneumatisation & \multicolumn{3}{c}{$5(6.5 \%)$} \\
\hline
\end{tabular}


Table-3: Distribution of different sinonasal variations in the study population $(n=76)$

\begin{tabular}{|lcl|}
$\begin{array}{l}\text { Type of anatomical } \\
\text { variation }\end{array}$ & $\begin{array}{c}\text { Present } \\
\mathbf{n}(\%)\end{array}$ & P value \\
DNS & $49(64.5 \%)$ & 0.012 \\
Concha bullosa & $15(19.7 \%)$ & \\
Agger nasi & $14(18.4 \%)$ & \\
Septal pneumatisation & $5(6.5 \%)$ & \\
Onodi cell & $3(3.9 \%)$ & \\
Haller cell & $2(2.6 \%)$ & \\
Paradoxical MT & $2(2.6 \%)$ & $<0.001$ \\
Uncinate process & $0(0 \%)$ & \\
pneumatisation & & \\
Total & $68(89.5 \%)$ & \\
\hline
\end{tabular}

Genderwise, anatomical variations were seen more in males but the difference was not statistically significant (Table-1). Some variations were seen more on the right side while others on the left. Some variations were present bilaterally. The difference was not statistically significant (Table-2). The presence of DNS was statistically significant in the study population ( $p$ value 0.012 ). For other variations which were less common, their absence in the study population was statistically significant with $\mathrm{p}$ values less than 0.001 in nonparametric chi square test (Table-3). The age group 14 to 30 showed maximum variations though not significant statistically (Table-4).

\begin{tabular}{|c|c|c|}
\hline \multicolumn{3}{|c|}{$\begin{array}{l}\text { Table-4: Sinonasal anatomical variations in } \\
\text { different age groups }\end{array}$} \\
\hline $\begin{array}{l}\text { Age group } \\
\text { (years) }\end{array}$ & $\begin{array}{l}\text { Presence of at least } \\
\text { one anatomical } \\
\text { variation } n(\%)\end{array}$ & P value \\
\hline 14 to 30 & $34(44.7 \%)$ & \\
\hline 31 to 45 & $24(31.5 \%)$ & \\
\hline 46 to 60 & $8(10.5 \%)$ & 0.180 \\
\hline$>60$ & $2(2.6 \%)$ & \\
\hline Total & $68(89.5 \%)$ & \\
\hline
\end{tabular}

\section{DISCUSSION}

In our study, out of 76 patients, 68 (89.5\%) had at least one type of anatomical variation while 8 $(10.5 \%)$ had no variation. This was similar to studies by Kaygusuz et al and Sarika et al where they found anatomical variations in $89.4 \%$ and $81.11 \%$ respectively. ${ }^{13,14}$ Other studies, however, report lower incidences ( $70 \%$ by Kanagaraj et al, $56.7 \%$ by Swain et al and $51.9 \%$ by Adeel et al). ${ }^{15-17}$ This difference in prevalence of anatomical variations of nose and PNS could be due to the result of discrepancies in analyzing and studying methods, definitions, racial varieties and the accuracy of study. ${ }^{18,19}$

The most common anatomical variant in our study was DNS, occurring in $49(64.5 \%)$ patients. This was comparable to the absolute frequencies of DNS in other studies done by Sharma et al (68\%) and Yadav et al (68\%) in Nepal but was quite high as compared to those done by Maru et al and Dua et al in India. ${ }^{20-23}$ However, in the study by Yadav et al, DNS was only the second most common variation after AN. Geographic variation might be the cause for high prevalence in our study. In yet another study from Nepal, Badhu et al have found DNS in 55 $\%$ of patients with associated nasal diseases. ${ }^{24}$ This also hints that DNS might be an important factor in causing nasal diseases and symptoms.

The second most common variation in our study was CB, seen in 15 (19.7\%) patients. Other studies from Nepal have reported the incidences as $27 \%$ and $35.9 \% .{ }^{20,21} \mathrm{CB}$ is referred to as pneumatisation of the middle turbinate. The reported prevalence of $\mathrm{CB}$ in literature varies widely from $14-80 \% .{ }^{25}$ Presence of $\mathrm{CB}$ is believed to block the ostiomeatal complex (OMC); thereby causing sinus disease. It also limits the exposure of surgical field during ESS. However, the relationship of concha bullosa to paranasal sinus disease continues to be debated.

The third most common variation in our study was AN, seen in $14(18.4 \%)$ patients. This was in contrary to a Nepalese study done by Yadav et al where they found AN in $75.8 \%$ of their patients making it the most common sinonasal anatomic variation. ${ }^{21}$ The international literature has reported the prevalence of $\mathrm{CB}$ across a wide range; from 5 to $8 \%$ in a study by Kayalioglu et al to as high as $98.5 \%$ in a study by Bolger. ${ }^{26,}{ }^{27}$ Agger cells can obstruct the frontonasal outflow tract causing frontal sinusitis. So this is an important feature to be identified and if necessary to be cleared through frontal sinus surgery.

In our study, SP was seen in $5(6.5 \%)$ patients. The prevalence of septal pneumatisation varied from $0 \%$ to $36.4 \%$ in studies done by Mohammad et al and Swain et al. ${ }^{16,17}$ Like DNS, prominent SP may block the ventilation and drainage of the middle meatus thereby causing sinus pathology. Therefore, it becomes important find out the presence of SP in patients with nasal symptoms. At times, it also becomes necessary to correct it surgically if identified as a cause for the disease process.

In our study, we found OC in 3 (3.9\%) patients. The rate of $\mathrm{OC}$ in previous studies has a very wide range (3.4-51\%). ${ }^{6}$ Onodi cells are posterior ethmoid cells that extend posteriorly far laterally and sometimes superior to the sphenoid sinus, lying medial to the optic nerve. If OC is present, the surgeon should be extra careful during posterior ethmoidectomy because the optic nerve may be at risk.

We found HC in 2 (2.6\%) patients. The rate of HC was ranging from 2 to $56.6 \%$ in the literature. ${ }^{5,26}$ Haller's cells are ethmoid air cells that project beyond the limits of the ethmoid capsule into the maxillary sinus. They grow into the floor of the orbit and if enlarged can constrict the posterior aspect of the ethmoidal infundibulum and superior medial portion of maxillary sinus osteum. This is especially likely to 
occur if the cells become infected. Therefore, HC could be involved in pathology of maxillary sinuses and might need to be addressed during planned ESS.

In our study, we found PCMT in 2 (2.6\%) patients. If the convexity of the middle concha is on the lateral side, it is referred as PCMT. The rates of PCMT are ranging from 15 to $26 \%$ in the literature. ${ }^{26}$ The major consequence of this anatomical variation is narrowing of the middle meatus which can lead to obstruction of infundibular drainage. The size and degree of convexity of the middle concha might be an important factor to cause the obstruction which will lead to sinonasal diseases.

In our study, we did not find UPP in any of our patients. Pneumatization of uncinate process refers to an aeration of air cells into the uncinate process. The uncinate projects from the ethmoid bone to the ethmoid process of inferior nasal concha. Pneumatised uncinate process can impair sinus ventilation especially in the anterior ethmoid, frontal recess and infudibulum regions and can cause a variety of sinonasal symptoms. This entity is observed relatively rare, when compared to the other sinonasal anatomical variations. The rate of UP pneumatization in previous studies has been reported to be about $0.4-9 \%{ }^{7,28}$

Genderwise, anatomical variations were seen more in males in our study but the difference was not statistically significant. This is in contrast to other studies which show females affected more..$^{21,26,29}$ While they argue that the hormonal changes in females during the various stages of life might influence the occurrence of sinonasal symptoms, our study suggests that there might not be gender predilection of any statistical significance.

As far as laterality was concerned, in our study, some variations were seen more on the right side while others on the left. Some variations were present bilaterally. The difference was not statistically significant. This hints that sinonasal anatomical variations do not have any predilection to right or left side.

Among all the variations studied, the presence of DNS was statistically significant in the study population ( $p$ value 0.012 ). For other variations which were less common, their absence in the study population was statistically significant with $\mathrm{p}$ values less than 0.001 in nonparametric chi square test. This not only hints to the widespread prevalence of DNS in our community but also associates DNS as an important factor for causing sinonasal symptoms. This also warrants proper addressing of DNS in patients with sinonasal symptoms.

The age group 14 to 30 years showed maximum variations though not significant statistically followed by age group 31 to 45 years. Similar age groups have been reported in other studies. ${ }^{21}$, 29 This is the most active age group and comprises the most productive age group of our society.

The most common sinonasal anatomic variation seen in our patients with sinonasal symptoms was DNS followed by $\mathrm{CB}$ and AN. Therefore, during management of such patients, these variations need to be addressed, if required, surgically. Proper knowledge of both common and uncommon sinonasal variations in our community could help in better surgical planning and overall management of sinonasal disorders.

\section{ACKNOWLEDGEMENTS}

Authors would like to acknowledge Dr. Nischal Dhakal, lecturer at the Department of Community Medicine, NMCTH for his help with statistics.

\section{REFERENCES}

1. Zinreich SJ. Rhinosinusitis: radiologic diagnosis. Otolaryngol Head Neck Surg 1997; 117: S27-34.

2. Ludwick JJ, Taber KH, Manolidis S, Sarna A, Hayman LA. A computed tomographic guide to endoscopic sinus surgery: axial and coronal views. J Comput Assist Tomogr 2002; 26: 317-22.

3. Kantarci M, Karasen RM, Alper F, et al. Remarkable anatomic variations in paranasal sinus region and their clinical importance. Eur J Radiol 2004; 50: 296302.

4. Sivasli E, Sirikçi A, Bayazýt YA, et al. Anatomic variations of the paranasal sinus area in pediatric patients with chronic sinusitis. Surg Radiol Anat 2003; 24: 400-5.

5. Azila A, Irfan M, Rohaizan Y, et al. The prevalence of anatomical variations in osteomeatal unit in patients with chronic rhinosinusitis. Med J Malaysia 2011; 66: 191-4.
6. Stallman JS, Lobo JN, Som PM. The incidence of concha bullosa and its relationship to nasal septal deviation and paranasal sinus disease. Am J Neuroradiol 2004; 25: 1613-8.

7. Fadda GL, Rosso S, Aversa S, et al. Multiparametric statistical correlations between paranasal sinus anatomic variations and chronic rhinosinusitis. Acta Otorhinolaryngol Ital 2012; 32: 244-51.

8. Eweiss AZ, Khalil HS. The prevalence of frontal cells and their relation to frontal sinusitis: a radiological study of the frontal recess area. ISRN Otolaryngol 2013; 2013: 687582.

9. Mathew R, Omami G, Hand A, et al. Cone beam CT analysis of Haller cells: prevalence and clinical significance. Dentomaxillofac Radiol 2013; 42: 20130055.

10. Nouraei SA, Elisay AR, Dimarco A, et al. Variations in paranasal sinus anatomy: implications for the 
pathophysiology of chronic rhinosinusitis and safety of endoscopic sinus surgery. J Otolaryngol Head Neck Surg 2009; 38: 32-7.

11. Tomovic S, Esmaeili A, Chan NJ, et al. High-resolution computed tomography analysis of the prevalence of Onodi cells. Laryngoscope 2012; 122: 1470-3.

12. Alkire BC, Bhattacharyya N. An assessment of sinonasal anatomic variants potentially associated with recurrent acute rhinosinusitis. Laryngoscope 2010; 120: 631-4.

13. Kaygusuz A, Haksever M, Akduman D, Aslan S, Sayar Z. Sinonasal anatomical variations: their relationship with chronic rhinosinusitis and effect on the severity of disease-a computerized tomography assisted anatomical and clinical study. Indian J Otolaryngol Head Neck Surg 2013; 66: 260-6.

14. Sarika KP, Mandke ND, Bahetee BH. Anatomic Variations Of Paranasal Sinuses In Patients With Chronic Sinusitis And Their Correlation with CT Scan Study. Int J Cur Res Rev 2015; 7: 35-9.

15. Kanagaraj R, Subramanian BC, Jesudoss AC, et al. Variations of CT scan in sinusitis. J Evid Based Med Healthc 2017; 4: 983-4.

16. Swain L, Singh M, Routray PN. Retrospective analysis of Anatomical Variations of Paranasal Sinuses on Multidetector Computed Tomography A Randomized Cross-Sectional Study. Ann Int Med Den Res 2018; 4: 15-21.

17. Adeel M, Rajput MS, Akhter S, Ikram M, Arain A, Khattak YJ. Anatomical variations of nose and paranasal sinuses;CT scan review. J Pak Med Assoc 2013; 63: 317-9.

18. Daghighi M, Daryani A, Nezad KC et al. Evaluation of anatomic variations of paranasal sinuses. Internet J Otorhinolaryngol 2007; 7: 1-4.

19. Stammberger HR and Kennedy DW. Paranasal Sinuses: Anatomic Terminology and Nomenclature. Ann Otol, Rhinol and Laryngol 1995 (Suppl); 167: 7-16.
20. Sharma BN, Pant OB, Lohani B, Khanal U. Computed Tomography in the Evaluation of Pathological Lesions of Paranasal Sinuses. J Nepal Health Res Counc 2015; 13: 116- 20.

21. Yadav RR, Ansari MA, Humagain M, Mishra D. Assessment of anatomical variations of nose and paranasal sinuses in multidetector computed tomography. J Inst Med 2017; 39: 49-54.

22. Maru YK, Gupta V. Anatomic variations of the bone in sinonasal C.T. Indian J Otolaryngol Head Neck Surg 2001; 53: 123-8.

23. Dua K, Chopra H, Khurana A, Munjal M. CT scan variations in chronic sinusitis. Indian $J$ Radiol Imaging 2005; 15: 315-20.

24. Badhu B, Dulal S, Kumar S, Thakur S, Sood A, Das H. Epidemiology of chronic dacryocystitis and success rate of external dacryocystorhinostomy in Nepal. Orbit 2005; 24: 79-82.

25. Jones NS. CT of the paranasal sinuses: a review of the correlation with clinical, surgical and histopathological findings. Clin Otolaryngol Allied Sci 2002; 27: 11-7.

26. Bolger EW, Butzin CA, Parsons DS. Paranasal sinus bony anatomic variations and mucosal abnormalities: CT analysis for endoscopic sinus surgery. Laryngoscope 1991; 101: 56-64.

27. Kayalioglu G, Oyar O, Govsa F. Nasal cavity and paranasal sinus bony variations: a computed tomographic study. Rhinology 2000; 38: 108-13.

28. Zinreich SI, Mattox DE, Kennedy DW, Chisholm HL, Diffley DM, Rosenbaum AE. Concha bullosa: CT evaluation. J Comput Assist Tomogr 1988; 12: 778-84.

29. Sahu A, Mukherjee SN, Rabin S, Praneeth K, Sahu V, Kavita G. Computerised Tomographic Evaluation of Structural Variations in Sinonasal Region and its Clinical Correlation. Int J Clin Exp Otolaryngol 2017; 3: 78-86. 